\title{
EKSTRAKSI DAN KARAKTERISASI MINYAK ATSIRI BUNGA KENANGA (Cananga odorata) DAN APLIKASINYA SEBAGAI PENOLAK NYAMUK PADA LOTION DAN PARFUM
}

\author{
J. J. Setia Budi*, N. L. Yuli Damayanti, Y. Rama Dhani, dan N. P. Antari Dewi \\ Jurusan Kimia FMIPA Universitas Udayana, Bukit Jimbaran, Bali \\ *Email: jeremyjordany@gmail.com
}

\begin{abstract}
ABSTRAK
Tujuan penelitian ini adalah untuk mengetahui karakteristik minyak atsiri bunga kenanga (Cananga odorata) hasil destilasi uap serta aplikasinya sebagai lotion dan parfum penolak nyamuk. Hasil karakterisasi minyak atsiri bunga kenanga yang ditinjau dari warna, bau, dan indeks-biasnya telah memenuhi standar kualitas minyak atsiri bunga kenanga menurut SNI 06-3949-1005. Namun demikian, bobot jenisnya yang sebesar 1,034 g/mL tidak sesuai dengan SNI. Hasil analisis komponen kimia penyusun minyak atsiri menggunakan GC-MS (Gas Chromatography-Mass Spectrometry) menunjukkan bahwa ada beberapa komponen utama dalam minyak atsiri yang teridentifikasi diantaranya yaitu benzyl benzoate, caryophyllene, linalool dan eugenol. Selanjutnya, uji efektivitas minyak atsiri bunga kenanga sebagai penolak nyamuk dalam bentuk lotion dan parfum menghasilkan bahwa minyak atsiri bunga kenanga dalam bentuk lotion lebih efektif mengusir nyamuk hingga $100 \%$ pada konsentrasi minyak kenanga 7,5\%, sedangkan dalam bentuk parfum dapat mengusir nyamuk $100 \%$ pada konsentrasi $20 \%$.
\end{abstract}

Kata kunci: Cananga odorata, destilasi uap, minyak atsiri, penolak nyamuk

\begin{abstract}
The purpose of this research was to characterize the essential oil of Cananga flower (Cananga odorata) extracted using vapor distilation technique and to apply it as lotion and perfume for mosquito repellent. The charaterization of the essential oil showed that the colour, odour, and diffraction index of the Cananga essential oil have meet the quality standard of Indonesian National Standard which is SNI 06-3949-1005. However, the density of the essential oil, which was of $1.034 \mathrm{~g} / \mathrm{mL}$ did not meet the requirement. The results of GC-MS (Gas Chromatography - Mass Spectrometry) analysis described that there were some main components in the Cananga essential oil such as benzyl benzoate, caryophyllene, linalool and eugenol. Furthermore, examination of the effectivity of the essential oil as mosquito repellent showed that the application of the Cananga essential oil as lotion was found to be more effective than as perfume in driving out $100 \%$ mosquitoes which were at the concentration of Cananga oil of $7.5 \%$ and of $20 \%$, respectively.
\end{abstract}

Keywords: Cananga odorata, essential oil, mosquito repellent, vapor distillation

\section{PENDAHULUAN}

Bunga kenanga yang berasal dari Indonesia khususnya Bali yaitu bunga kenanga spesies Cananga odorata forma macrophylla dapat menghasilkan minyak kenanga (Luqman \& Rahmayanti, 1994). Minyak kenanga merupakan salah satu jenis minyak atsiri yang memiliki aroma yang khas yaitu beraroma floral dan berwarna kuning muda hingga kuning tua. Pada umumnya minyak atsiri kenanga diperoleh dengan cara mengisolasi bunga kenanga melalui metode destilasi uap. Di dalam minyak atsiri bunga kenanga terkandung senyawa-senyawa yang diduga mempunyai efek penolakan nyamuk yaitu senyawa linalool, geraniol, dan eugenol (Sudjari, Prijadi, \& Austin, 2007).

Semakin majunya jaman, hadir sebuah produk yaitu lotion penolak nyamuk yang dapat membuat nyamuk alergi dengan bau dan kandunganya. Lotion penolak nyamuk dikenal sebagai salah satu jenis pestisida rumah tangga yang digunakan untuk melindungi kulit tubuh dari gigitan nyamuk. Di dalamnya terkandung zat - zat kimiawi seperti DEET, permetrin, picaridin. DEET adalah bahan kimia aktif yang 
terdapat pada produk pembasmi serangga. Efek samping yang paling cepat, saat terlalu sering menggunakan lotion penolak nyamuk dalam jangka waktu yang panjang, adalah terkena alergi pada permukaan kulit, iritasi, dan eritema atau kemerahan pada kulit, dan paling parah penggunaan DEET > 30\% dapat menyebabkan kanker kulit (Soedarto, 1992). Dengan demikian pembuatan lotion penolak nyamuk dari bahan alami menjadi sangat penting untuk menghindari efek samping tersebut (Kardinan, 2003). Membuat lotion penolak nyamuk dari minyak atsiri bunga kenanga merupakan salah satu solusi untuk mengusir nyamuk tanpa efek samping. Selain itu, membuat parfum dari minyak atsiri bunga kenanga sebagai penolak nyamuk juga sangat praktis untuk digunakan sehari-hari. Dengan memanfaatkan fungsi parfum sebagai anti nyamuk diharapkan dapat meminimalisir serangan nyamuk pada tubuh manusia.

Berdasarkan uraian di atas, pada penelitian ini dilakukan destilasi uap untuk menghasilkan minyak atsiri bunga kenanga. Penggunaan destilasi uap diharapkan dapat mengisolasi komponen yang mudah menguap atau bersifat volatile. Untuk mengetahui kualitas minyak atsiri bunga kenanga, dilakukan karakterisasi sifat fisik berdasarkan SNI 09-3949-1005 yang meliputi warna, bau, indeks bias, dan berat jenis. Analisa komponen minyak atsiri bunga kenanga dilakukan dengan menggunakan GC-MS untuk mengetahui senyawa penyusun minyak atsiri bunga kenanga. Sedangkan untuk mengetahui efektivitas minyak atsiri bunga kenanga sebagai penolak nyamuk dilakukan dengan mengaplikasikan minyak atsiri bunga kenanga yang diaplikasikan dalam bentuk lotion dan parfum dengan variasi konsentrasi minyak atsiri.

\section{MATERI DAN METODE}

\section{Bahan}

Bahan tanaman yang digunakan dalam penelitian ini adalah bunga kenanga (Cananga odorata) yang diambil dari Desa Tegalalang, Gianyar. Bahan biologi yang digunakan sebagai hewan uji adalah nyamuk yang diperoleh dari Laboratorium Parasitologi Fakultas Kedokteran Universitas Udayana. Bahan kimia yang digunakan adalah aquades, etanol sebagai control parfum, basis lotion sebagai kontrol lotion minyak atsiri.

\section{Alat Penelitian}

Alat-alat yang digunakan dalam penelitian ini yaitu : pisau, plastik wrap Piknometer $10 \mathrm{~mL}$, Refraktor Abbe, kandang nyamuk, kertas saring, botol semprot, seperangkat alat gelas dan seperangkat alat destilasi uap.

\section{Cara Kerja}

\section{Ekstraksi minyak atsiri dengan destilasi uap}

Bunga kenanga segar sebanyak $15 \mathrm{~kg}$ didestilasi-uap selama 6 jam sehingga minyak atsiri keluar dari kelenjar minyak dalam bunga kenanga. Selama proses destilasi berlangsung, partikel-parikel minyak pada bahan baku akan terbawa bersama uap dan dialirkan pada kondensor. Proses pengembunan terjadi di dalam alat kondensor, sehingga uap air yang bercampur dengan minyak akan mengembun dan tertampung di dalam wadah penampung. Setelah itu campuran air dan minyak dipisahkan. Fase air destilat dikeluarkan dan ditampung dengan botol penampung, kemudian ditambahkan natrium klorida untuk memisahkan kemungkinan adanya sisa-sisa minyak yang masih teremulsi dalam air, sehingga minyak yang teremulsi akan terpisah dan terlihat lebih jelas untuk pemisahan lebih lanjut. Sedangkan fase minyak destilat dikeluarkan dan ditampung pada botol vial. Minyak atsiri yang dihasilkan dari pemisahan di fase air selanjutnya digabung dengan destilat minyak atsiri hasil ekstraksi yang telah diperoleh sebelumnya.

\section{Karakterisasi minyak atsiri bunga kenanga}

Sifak fisik yang diuji berupa warna, bau, indeks bias dan berat jenis dar minyak atsiri bunga kenanga. Indeks bias diukur menggunakan alat Refraktrometer Abbe dan untuk berat jenis diukur menggunakan Piknometer $10 \mathrm{~mL}$. Kemudian hasil karakterisasi fisik tersebut dibandingkan dengan standard minyak atsiri menurut SNI 06-3949-1005.

\section{Pengukuran indeks bias}

Lensa refraktometer dibersihkan dari kotoran-kotoran dengan kapas yang telah 
dibasahi dengan alkohol. Air dialirkan melalui refractometer agar alat berada pada suhu pembacaan. Kemudian dicoba mengukur indeks bias air suling terlebih dahulu. Minyak atsiri diteteskan pada lensa prisma dengan pipet tetes. Setelah terlihat adanya perbedaan gelap dan terang, kemudian dibaca indeks biasnya pada angka yang ditunjukkan oleh skala.

\section{Pengukuran berat jenis}

Piknometer $10 \mathrm{~mL}$ kosong ditimbang terlebih dahulu, kemudian piknometer diisi minyak atsiri dan ditimbang lagi. Selanjutnya dilakukan perhitungan sebagai berikut :

Berat minyak atsiri $=$ berat piknometer yang telah terisi minyak atsiri - berat pikometer kosong.

$$
\rho=\frac{\text { hasil berat setelah pengurangan }}{\text { volume }}
$$

\section{Analisa komponen minyak atsiri bunga kenanga dengan metode GC-MS}

Minyak atsiri bunga kenanga hasil destilasi uap dianalisa menggunakan instrumen GC-MS dan diperoleh beberapa komponen utama yang sangat efektif sebagai penolak nyamuk yaitu geranil benzoate, caryophyllene, linalool dan eugenol.

\section{Uji efektivitas lotion dan parfum minyak kenanga sebagai penolak nyamuk}

Minyak atsiri hasil destilasi kemudian diaplikasikan kedalam basis lotion dan parfum. Lotion yang netral tanpa bahan pewangi atau bahan anti nyamuk lalu tambahkan minyak atsiri dengan variasi konsentrasi. Adapun konsentrasi minyak atsiri dalam dalam lotion adalah sebagai berikut:

1. Konsentrasi $0 \%=0 \mathrm{ml}$ minyak atsiri + $10 \mathrm{ml}$ basis lotion

2. Konsentrasi $7.5 \%=0.75 \mathrm{ml}$ minyak atsiri $+9.25 \mathrm{ml}$ basis lotion

3. Konsentrasi $20 \%=2 \mathrm{ml}$ minyak atsiri + $8 \mathrm{ml}$ basis lotion

4. Konsentrasi $40 \%=4 \mathrm{ml}$ minyak atsiri + $6 \mathrm{ml}$ basis lotion.

Sedangkan aplikasinya sebagai parfum, etanol ditambahkan minyak atsiri dengan variasi konsentrasi. Adapun konsentrasi minyak atsiri dalam parfum adalah sebagai berikut :

5. Konsentrasi $0 \%=0 \mathrm{ml}$ minyak atsiri + $10 \mathrm{ml}$ etanol

6. Konsentrasi $7.5 \%=0.75 \mathrm{ml}$ minyak atsiri $+9.25 \mathrm{ml}$ etanol

7. Konsentrasi $20 \%=2 \mathrm{ml}$ minyak atsiri + $8 \mathrm{ml}$ etanol

8. Konsentrasi $40 \%=4 \mathrm{ml}$ minyak atsiri + $6 \mathrm{ml}$ etanol.

Kemudian efektivitas penolak nyamuknya diuji dengan cara lotion dioleskan dan parfume disemprotkan masing - masing pada tangan kemudian dimasukkan pada kurungan nyamuk yang berisi 10 ekor nyamuk dan diamati berapa nyamuk yang hinggap selama 30 menit dengan pengulangan sebanyak 3 kali pada tiap konsentrasi.

\section{HASIL DAN PEMBAHASAN}

\section{Ekstraksi minyak atsiri bunga kenanga}

Dengan metode destilasi uap dilakukan ekstraksi minyak atsiri bunga kenanga yang selama 6 jam. Ekstraksi dilakukan sebanyak 5 kali, dimana dalam satu kali proses destilasi digunakan bunga kenanga sebanyak $3 \mathrm{~kg}$. Ekstraksi minyak atsiri bunga kenanga pada penelitian ini menghasilkan minyak atsiri bunga kenanga yang bewarna kuning muda dan berbau wangi segar khas kenanga sebanyak $50 \mathrm{ml}$.

\section{Karakterisasi minyak atsiri bunga kenanga}

Karakterisasi minyak atsiri bunga kenanga bertujuan untuk mengetahui kualitas minyak atsiri yang dihasilkan. Adapun karakterisasinya meliputi warna, bau, pengukuran indeks bias, dan berat jenis.

Berdasarkan data sifat fisik minyak atsiri bunga kenanga yang ditunjukkan pada Tabel 1, bahwa warna, bau, dan indeks biasnya memenuhi standar mutu minyak atsiri menurut SNI 06-3949-1005, sedangkan berat jenis minyak atsiri bunga kenanga tidak memenuhi standar mutu menurut SNI 06-3949-1005, 
Tabel 1 Sifat fisik minyak atsiri bunga kenanga

\begin{tabular}{ccc}
\hline Parameter & $\begin{array}{c}\text { Hasil destilasi } \\
\text { uap }\end{array}$ & $\begin{array}{c}\text { SNI 06-3949- } \\
\mathbf{1 0 0 5}\end{array}$ \\
\hline Warna & Kuning muda & $\begin{array}{c}\text { Kuning muda }- \\
\text { kuning tua }\end{array}$ \\
Bau & $\begin{array}{c}\text { Segar wangi khas } \\
\text { kenanga }\end{array}$ & $\begin{array}{c}\text { Segar khas } \\
\text { kenanga }\end{array}$ \\
Indeks Bias & $1,502(29 \mathrm{C})$ & $\begin{array}{c}1,493-1,503 \\
0\end{array}$ \\
Berat Jenis & $1,034 \mathrm{~g} / \mathrm{mL}$ & $0,904-0,9209$ \\
& $\left(29^{0} \mathrm{C}\right)$ & $\mathrm{g} / \mathrm{mL}\left(20^{0} \mathrm{C}\right)$ \\
\hline
\end{tabular}

dimana di dapatkan berat jenis yang lebih besar, hal ini kemungkinan dikarenakan perbedan suhu serta masih terdapat kandungan air dalam minyak atsiri sehingga mempengaruhi hasil penelitian.

\section{Analisa komponen minyak atsiri bunga kenanga}

Minyak atsiri bunga kenanga hasil destilasi uap dianalisa menggunakan instrumen GC-MS dan diperoleh 25 komponen penyusun minyak atsriri diantaranya geranil benzoate, caryophyllene, linalool dan Eugenol. Dimana eugenol dan linalool adalah senyawa yang sangat efektif sebagai penolak nyamuk (Indrawati, 2006).

Hasil spektra massa komponen minyak atsiri kenanga diperlihatkan dalam Gambar1.

\section{Efektivitas Lotion dan Parfum sebagai Penolak Nyamuk}

Efektivitas lotion dan parfum bunga kenanga sebagai penolak nyamuk diuji berasarkan pada banyaknya nyamuk yang hinggap pada tangan. Pengujian dilakukan di Laboratorium Parasitologi Fakultas Kedokteran Universitas Udayana. Dibutuhkan waktu 30 menit setiap kali pengujian dan dilakukan pengulangan sebanyak 3 kali dengan variasi konsentrasi minyak atsiri dalam lotion dan parfum. Mula-mula pengujian dilakukan dengan mengoleskan lotion pada tangan seperti penggunaan lotion pada umumnya, kemudian tangan dimasukkan pada kandang nyamuk yang berisi 10 nyamuk yang telah dilaparkan selama 2 hari. (a) Benzyl benzoate

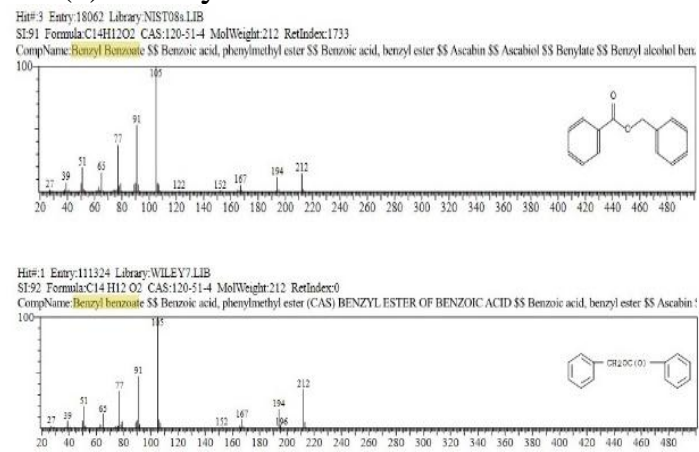

(b) Caryophyllene

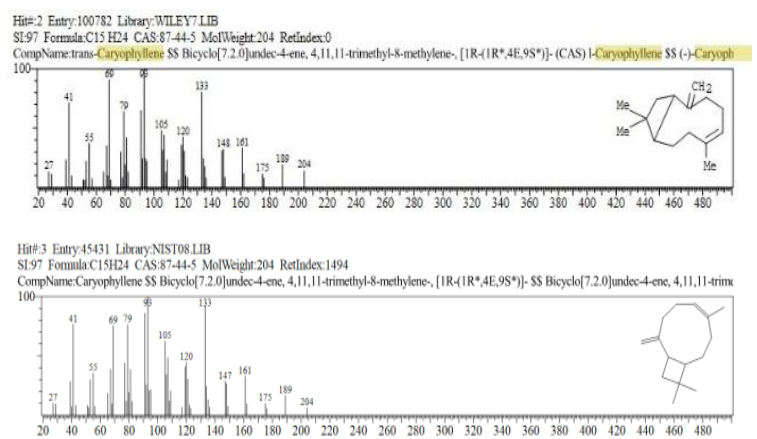

(c) Linalool

Hitt.1 Entry.17386 Libray NISTO8.LIB

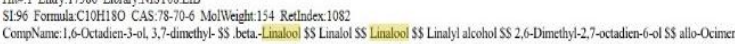

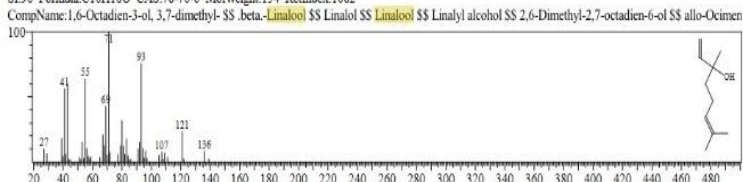

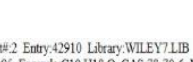

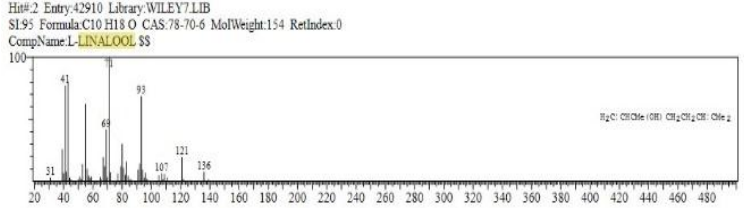

(d) Eugenol
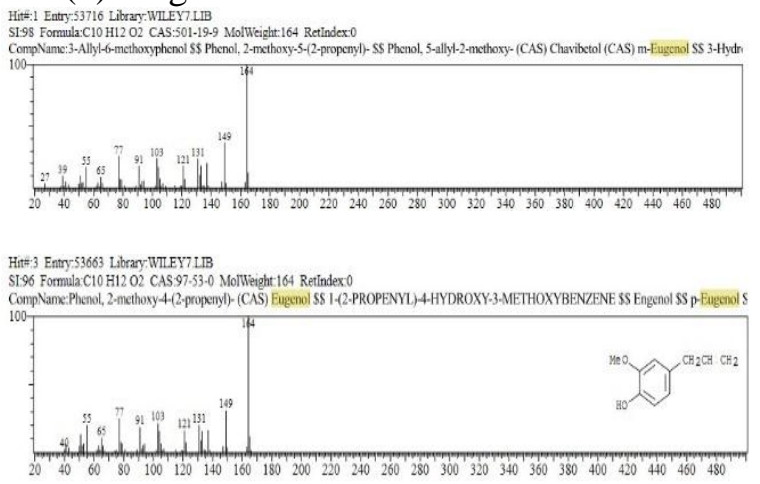

Gambar 1. Spektra massa Benzyl benzoate (a), Caryophyllene (b) Linalool (c) dan Eugenol (d) 
Tabel 2 Uji efektivitas lotion minyak atsiri bunga kenanga

\begin{tabular}{cccc}
\hline \multirow{2}{*}{$\begin{array}{c}\text { Konsentrasi pada } \\
\text { lotion minyak } \\
\text { atsiri }\end{array}$} & \multicolumn{3}{l}{ Nyamuk yang hinggap } \\
\cline { 2 - 4 } & I & II & III \\
\hline K. $0 \%$ & 5 & 3 & 6 \\
K. $7,5 \%$ & 0 & 0 & 0 \\
K. $20 \%$ & 0 & 0 & 0 \\
K. $40 \%$ & 0 & 0 & 0 \\
\hline
\end{tabular}

Tabel 3 Uji efektivitas parfum minyak atsiri bunga kenanga

\begin{tabular}{cccc}
\hline Konsentrasi pada & \multicolumn{3}{c}{ Nyamuk yang hinggap } \\
\cline { 2 - 4 } parfum minyak atsiri & I & II & III \\
\hline K. $0 \%$ & 9 & 10 & 9 \\
K. $7,5 \%$ & 4 & 2 & 1 \\
K. $20 \%$ & 0 & 0 & 0 \\
K. $40 \%$ & 0 & 0 & 0 \\
\hline
\end{tabular}

Hasilnya menunjukkan lotion dengan konsentrasi yang kecil $(7,5 \%)$ sudah efektif dalam menolak nyamuk $100 \%$. Sedangkan pengujian parfum dilakukan dengan menyemprotkan parfum pada tangan seperti penggunaan parfum pada umumnya, kemudian dilakukan uji yang sama dengan lotion. Parfum dengan konsentrasi 20\% sudah efektif dalam menolak nyamuk sebanyak $100 \%$. Perbedaan hasil ini dikarenakan pada penggunaan lotion dioleskan secara merata pada tangan layaknya penggunaan lotion pada umumnya. Sedangkan penggunaan parfum hanya disemprotkan di pergelangan tangan layaknya penggunaan parfum pada umumnya, sehingga pada konsentrasi minyak atsiri $0,75 \%$ masih ada nyamuk yang menempel. Berdasarkan uji efektivitas lotion dan parfum minyak atsiri yang telah dilakukan, didapatkan hasil seperti dalam Tabel 2 dan 3 di atas.

\section{SIMPULAN DAN SARAN}

\section{Simpulan}

Berdasarkan penelitian yang telah dilakukan, minyak atsiri bunga kenanga diekstraksi dengan metode destilasi uap selama 6 jam menghasilkan minyak atsiri yang memiliki sifat fisik berwarna kuning muda dan berbau khas serta memiliki nilai indeks bias yang telah memenuhi standard mutu menurut SNI 06-39491005 , kecuali berat jenisnya, hal ini dapat terjadi karena perbedaan suhu dan kemungkinan minyak masih mengandung air sehingga dapat mempengaruhi hasil. Minyak atsiri yang diaplikasikan pada lotion dan parfum pada penelitian ini efektif sebagai penolak nyamuk. Pada lotion dengan konsentrasi minyak atsiri $7,5 \%$ efektif menolak nyamuk $100 \%$, sedangkan pada parfum dengan konsentrasi $20 \%$ efektif menolak nyamuk $100 \%$.

\section{Saran}

Destilasi yang dilakukan akan lebih optimal apabila dilakuan selama 8 jam dan menggunakan alat yang bagus sehingga semua komponen yang terkandung dalam minyak atsiri tersepat dengan baik sehingga hasil yang diperoleh maksimal.

\section{UCAPAN TERIMAKSIH}

Pada kesempatan ini penulis mengucapkan terimakasih kepada Ibu Oka Ratnayani, S.Si., M.Si., Ph.D., Bapak Dr. I Made Sukadana, M.Si. dan Ibu Sri Rahayu Santi, S.Si., M.Si.

\section{DAFTAR PUSTAKA}

Armando, Rochim. 2009. Memproduksi minyak atsiri berkualitas penebar swadaya. Jakarta.

Badan Penelitian dan Pengembangan Daerah Kabupaten Blitar. 2006. Pengembangan bisnis minyak atsiri kenanga. Blitar.

Burdock, George A., and I. G. Carabin. 2001. Safety Assessment of Ylang-ylang (Cananga spp.) as a Food Ingredien. USA : Vero Beach FL 32960.

Dalimartha, S. 2009. Atlas Tumbuhan Obat Indonesia Jilid 5. Jakarta : Trubus Agriwidia.

Gandjar, Indrawati. 2006. Mikologi Dasar dan Terapan. Jakarta : Yayasan Obor Indonesia.

Guenter, E. 2011. Minyak atsiri jilid I. Universitas Indonesia. Jakarta 
Gunawan, D. dan Mulyani, S. 2004. Ilmu obat alam (Farmakognosi), jilid I. Jakarta : Penebar Swadaya.

Hernani dan Marwati T. 2006. Peningkatan mutu minyak atsiri melalui proses pemurnian. Balai Besar Litbang Pascapanen Pertanian. Bogor.

Kardinan, A. 2003. Tanaman Pengusir dan Pembasmi Nyamuk. Jakarta : Agro Media Pustaka.

Ketaren S. 1985. Pengantar Teknologi Minyak Atsiri. PN Balai Pustaka. Jakarta

Klowden, J.M, A.G. Held, and A.R. Bulla. 1983. Toxicity of Bacillus Thuringiensis subs. Israelenss to adult aegepty mosquitoes. Applied eviromental micobiologi

Leksono, A.S 1997. Perubahan Tingkat Toleransi Larva Aedes Aegepty L. (Diptera: Culicideae) terhadap Malation dengan Seleksi Delapan Generasi. Bandung : Institut Teknologi Bandung.
Luqman L \& Rahmayanti Y. 1994. Produksi dan Perdagangan Minyak Atsiri. Penebar Swadaya. Jakarta

Nanan, Nurdjannah. 2005. Minyak Ylang-ylang dalam Aromaterapi dan Prospek Pengembangannya di Indonesia. Bogor : Balai Besar Penelitian dan Pengembangan Pascapanen Pertanian.

Skaria, B.P., 2007. Aromatics Plants. New Delhi : Laxmi Art Creation.

Soedarto. 1992. Entomologi Kedokteran. Jakarta : EGC

Sudjari, Prijadi, Bambang and Austin, Rifcka. 2007. Uji potensi ekstrak bunga kenanga (cananga odorata) sebagai repellent terhadap nyamuk culex sp.

Suharmiati dan Lestari. 2007. Tanaman Obat dan Ramuan Tradisional untuk Mengatasi Deman Berdarah Dengue. Jakarta : Agromedia Pustaka 